\title{
ESTUDO SOBRE A CONTAMINAÇÃO DE JALECO POR Staphylococcus COMO SUBSIDIO PARA O CONHECIMENTO DAS INFECÇÕES CRUZADAS
}

\author{
Ana Cláudia Pedreira de ALMEIDA ${ }^{1}$ \\ Roberto Lourenço de SOUZA JÚNIOR ${ }^{2}$ \\ Sávio Domingos de OLIVEIRA JÚNIOR ${ }^{3}$ \\ Taís Almeida Vital RIBEIRO ${ }^{4}$ \\ Denismar Alves NOGUEIRA ${ }^{5}$ \\ Jorge Kleber CHAVASCO ${ }^{6}$
}

${ }^{1}$ Cirurgiã-dentista, Doutora em Biologia Funcional e Molecular, Professora Adjunta da Faculdade de Odontologia da Universidade Federal de Alfenas- UNIFAL-MG - ana.claudia@ unifal-mg.edu.br

${ }^{2}$ Cirurgião-dentista pela Universidade Federal de Alfenas- UNIFAL-MG- robertojunior 90@ @otmail.com

${ }^{3}$ Cirurgião-dentista pela Universidade Federal de Alfenas- UNIFAL-MG- saviojuniorgp@ hotmail.com

${ }^{4}$ Cirurgiã-dentista pela Universidade Federal de Alfenas- UNIFAL-MG- tata kings@ @otmail.com

${ }_{6}^{5}$ Professor de Estatística da Universidade Federal de Alfenas- UNIFAL-MG- denismar.nogueira@unifal-mg.edu.br

${ }^{6}$ Professor Titular de Microbiologia da Universidade Federal de Alfenas- UNIFAL-MG- jkchavasco@uol.com.br

Recebido em: 20/03/2015 - Aprovado em: 13/08/2015 - Disponibilizado em: 30/10/2015

\begin{abstract}
RESUMO
Para prevenir a contaminação por agentes infecciosos os profissionais de saúde adotam medidas de biossegurança no ambiente de trabalho, uma delas é a utilização do jaleco. Bactérias podem ser veiculadas pelo jaleco e o uso do mesmo fora do ambiente de trabalho, além de constituir falta de higiene, representa um risco importante de disseminação de doenças. Esse trabalho teve como objetivo de avaliar qualitativamente e quantitativamente a presença de Staphylococcus em jalecos utilizados por alunos do curso de Odontologia da Universidade Federal de Alfenas-MG. O material foi colhido dos jalecos na região do bolso, punho e peito por meio do contato das placas tipo RODAC contendo mannitol salt ágar para isolamento de Staphylococcus. As placas foram incubadas a $37^{\circ} \mathrm{C}$ por 48 horas. Foi feita a análise microbiológica através da contagem de colônias, provas bioquímicas e antibiograma. Os dados foram analisados por meio dos testes de Kruskal-Wallis, Mann-Whitney e coeficiente de correlação de Spearman. Observou-se a presença de Staphylococcus em jalecos utilizados por alunos do curso de Odontologia. Não houve diferença significativa entre as três áreas de coleta em relação ao nível de contaminação. Não houve correlação entre o tempo em que o jaleco se encontrava em uso com contaminação nas três áreas analisadas. A maioria dos alunos higienizava seu jaleco semanalmente e o tecido predominante foi a microfibra. Todos os entrevistados tinham consciência do risco e utilizam o jaleco somente no ambiente clínico. Concluímos que os jalecos dos alunos do curso de Odontologia da UNIFAL-MG apresentaram contaminação por Staphylococcus sp podendo assim servir como fonte potencial de infecções cruzadas.
\end{abstract}

Palavras-chave: Jaleco. Biossegurança. Staphylococcus. Contaminação. Infecção cruzada. 


\title{
STUDY ON THE LAB COAT CONTAMINATION BY Staphylococcus FOR KNOWLEDGE OF CROSS INFECTION
}

\begin{abstract}
To prevent contamination by infectious agents health professionals adopt biosecurity measures in the workplace, one of them is to use the coat. Bacteria can be transmitted by using the same coat and outside the work environment, besides being poor hygiene is a major risk of spreading disease. This study aimed to evaluate qualitative and quantitatively the presence of Staphylococcus in lab coats used by students of Dentistry, Federal University of Alfenas - MG. The material was collected in the pocket of coats, wrist and chest area through contact with mannitol agar salt RODAC plates for isolation of Staphylococcus. The plates were incubated at $37{ }^{\circ} \mathrm{C}$ for 48 hours. Microbiological analysis was performed by counting colonies, biochemical tests and antibiotic sensitivity. Data were analyzed by Kruskal - Wallis, Mann - Whitney and Spearman correlation coefficient tests. We observed the presence of Staphylococcus in coats used by dental students. There was no significant difference on the level of contamination among the three collection areas. There was no correlation between the time of the coat use and contamination in the three areas analyzed. Most students report to clean their lab coat weekly and the predominant lab coat material was microfiber type. All respondents were aware of the risk and use the lab coat only in the clinical setting. We conclude that Dentistry student coats, from UNIFAL-MG, presented contamination by Staphylococcus sp and it can thus serve as a potential source of crossinfection.
\end{abstract}

Keywords: Lab Coat, Biosecurity, Staphylococcus. Contamination. Cross-infection.

\section{INTRODUÇÃO}

Dentro de um ambiente clínico a infecção cruzada, é a transmissão de agentes infecciosos entre indivíduos. Embora seja um aspecto destacado somente com o advento da síndrome de imunodeficiência adquirida (AIDS), este tema passou a ser foco principal de muitos congressos e, principalmente, entre os profissionais que passaram a se preocupar com a biossegurança para sua proteção e a de seus pacientes.

A utilização do jaleco por profissionais de saúde como médicos, dentistas, nutricionistas, farmacêuticos, enfermeiros, psicólogos, fisioterapeutas e estudantes das diversas áreas de saúde fora de seu ambiente de trabalho, pode constituir um risco higiênico sanitário dado à possibilidade de contaminação cruzada entre o avental, mãos, alimento e pacientes (CARDOSO et al., 2010).

Os jalecos dos profissionais da área da saúde passam a ser o primeiro sítio de contato em termos de indumentária com a pele, líquidos e secreções dos pacientes, tornando-se com isto um verdadeiro fômite. Bactérias multirresistentes, que podem provocar doenças como faringites, otites, pneumonia, tuberculose e até mesmo a morte, são carregadas para lugares públicos e retornam das ruas para consultórios médicos,

Revista da Universidade Vale do Rio Verde, Três Corações, v. 13, n. 2, p. 152-161, 2015 
odontológicos, enfermarias e salas de cirurgia nos jalecos dos mais diversos profissionais de saúde. Frequentemente, a seriedade da questão é negligenciada por arrogância ou desconhecimento de alguns conceitos básicos de microbiologia (CARVALHO, 2009).

Staphylococcus aureus é um dos principais patógenos associados com infecções adquiridas na comunidade e no ambiente hospitalar. A colonização por este micro-organismo apresenta-se de forma assintomática, mas é de grande importância clínica e epidemiológica quando indivíduos colonizados são o veículo de transporte desta bactéria no ambiente hospitalar. Os profissionais da saúde têm sido apontados, como importantes na disseminação do Staphylococcus aureus e do Staphylococcus aureus resistente à meticilina (MRSA) no ambiente hospitalar (FENALTE; GELATTI, 2012).

Em restaurantes e lanchonetes da região hospitalar de muitas cidades, observam-se, diariamente, médicos, enfermeiros, odontólogos e outros profissionais de saúde paramentados com seus aventais de mangas compridas, gravatas, estetoscópios no pescoço e até mesmo vestimentas específicas para áreas cirúrgicas (DIAS JÚNIOR, 2008).

\section{MATERIAL E MÉTODOS}

Foram avaliados os jalecos de 30 alunos do curso de Odontologia da UNIFALMG, aleatoriamente selecionados, cujo modelo foi o de manga longa, fechado frontalmente com botões, colarinho alto, e o comprimento até a altura dos joelhos. Foram analisadas três áreas dos jalecos em relação aos níveis de contaminação: bolso, punho e peito. A coleta das informações relativas ao sexo, idade, frequência de higienização, tempo de uso, tipo de tecido dos jalecos se deu a partir da aplicação de um questionário a todos os alunos participantes e que tenham assinado o Termo de Consentimento Livre e Esclarecido, autorizando sua participação na pesquisa. O projeto foi aprovado pelo comitê de ética em pesquisa da UNIFAL-MG com o número 022/2012.

O material foi coletado após o atendimento nas clinicas odontológicas devendo estar incluído, no atendimento, o uso da caneta de alta rotação. O material foi colhido por meio do contato das placas de superfície tipo RODAC (Replicate Organisms Direct Agar Plates) contendo Mannitol Salt Agar. As regiões do avental escolhidas foram o bolso inferior correspondente a mão dominante, porção radial interna do punho da mão dominante e região do peito do lado direito. As placas foram tocadas na superfície 
do tecido por 30 segundos e incubadas $37^{\circ} \mathrm{C}$ por 48 horas. Após a incubação foram contadas as unidades formadoras de colônia por placa (UFC/placa) RODAC com $20 \mathrm{~cm}^{2}$ de área. A contagem das unidades formadoras de colônias foi feita num contador de colônias. As colônias suspeitas de serem Staphylococcus foram submetidas aos métodos de identificação para Staphylococcus como o método de Gram, catalase, DNAse e coagulase. Das trinta placas foram isoladas aleatoriamente 19 colônias que foram submetidas ao antibiograma pela técnica de Bauer et al. (1966) utilizando os seguintes antibióticos da marca $\mathrm{DME}^{\circledR}$ : Amoxilina + Clavulanato, Sulfazotrim, Oxaciclina, Norfloxacina, Linezulida, Clindamicina, Ciprofloxacina, Azitromicina e Vancomicina. Os dados obtidos foram submetidos a análise estatística por meio dos testes de KruskalWallis, Mann-Whitney e coeficiente de correlação de Spearman considerando quando $5 \%$ de significância.

\section{RESULTADOS E DISCUSSÃO}

Do ponto de vista teórico o jaleco deveria ser utilizado somente no local de trabalho, mas na prática, entretanto, não é isto que acontece. Os jalecos tornam-se contaminados durante atendimentos, sugerindo que é um veículo potencial para transmissão de micro-organismos, o que pode vir a causar infecções cruzadas associadas a cuidados de saúde (NESI et al., 2006; LOVEDAY et al., 2007; CARDOSO et al., 2010).

Neste trabalho, observou-se que dos 30 alunos do curso de Odontologia participantes, 09 (30\%) eram do sexo masculino e $21(70 \%)$ do sexo feminino, a faixa etária predominante foi de 21 a 24 anos. Embora a maioria dos jalecos tenha sido usada por mulheres não houve diferença entre a contaminação dos seus jalecos em relação aos dos homens (teste de Mann-Whitney).

O tecido de predomínio para confecção dos jalecos pesquisados foi a microfibra $22(73,33 \%)$ seguido pelo Oxford 8 (26,67\%). A microfibra é um tecido de fibra muito fina, utilizada na forma de multifilamentos, impermeável, que permite a saída de suor e ar. Da mesma forma, o tecido predominante usado pelos estudantes de Odontologia da UFRN foi a microfibra (NESI et al., 2006).

A maioria dos entrevistados informou no preenchimento do questionário que higienizavam seu jaleco com uma frequência semanal $19(63,33 \%)$. Apenas, $4(13,33 \%)$ higienizavam o jaleco após cada uso. Os jalecos haviam sido reutilizados nos atendimentos clínicos por duas $(26,67 \%)$, três $(26,67 \%)$, quatro $(23,33 \%)$ vezes antes da

Revista da Universidade Vale do Rio Verde, Três Corações, v. 13, n. 2, p. 152-161, 2015 
coleta do material e (20\%) usaram o jaleco uma vez antes da coleta. De acordo com Silva et al. (2012), o jaleco deve ser preferencialmente descartável; caso seja reutilizável, deve ser limpo ao final do período de trabalho com água e sabão, evitando-se contato com outras roupas de uso comum.

Outro achado importante foi a observação de que todos os participantes da pesquisa (100\%) quando questionados se tinham consciência de que o uso do jaleco fora do ambiente clínico poderia ser uma fonte potencial de infecções cruzadas, responderam que sim, ou seja, tem consciência do risco e utilizam o jaleco somente no ambiente clínico. Isto pode ser reflexo de uma ação extensionista em desenvolvimento desde 2010 na Universidade Federal de Alfenas-UNIFAL-MG, o "PUCA-
Saúde - Projeto do Uso Consciente do Avental".

Vários estudos comprovaram a contaminação dos jalecos e verificaram que os locais de maior contaminação foram: bolsos, punhos e região da cintura. Isso pode ser associado ao contato direto destes locais com o paciente e ao contato indireto com superfícies ambientais, estetoscópios, entre outros (PILONETTO et al., 2004; UNEKE, IJEOMA, 2010, OLIVEIRA; SILVA, 2013). No presente estudo, os níveis de contaminação para as três áreas pesquisadas encontram-se na Tabela1. Quanto ao nível de contaminação nas áreas pesquisadas os valores obtidos a partir dos três sítios (peito, bolso e punho) demonstraram que não houve diferença entre os mesmos $(p=0,8234)$ quando se realizou o teste de Kruskal-Wallis.

Tabela 01 - Médias, medianas, mínimos, máximos, erros padrões das médias e desvios padrões para contagem das bactérias (UFC) por $20 \mathrm{~cm}^{2} /$ placa RODAC, das áreas correspondentes ao peito, bolso e punho de jalecos utilizados por alunos de odontologia durante procedimentos clínicos. Alfenas, MG. 2012.

\begin{tabular}{ccccccc}
\hline Área & Média & Mediana & Mínimo & Máximo & $\begin{array}{c}\text { Erro padrão da } \\
\text { média }\end{array}$ & Desvio padrão \\
\hline Peito & 13,67 & 11,25 & 00 & 60 & 2,47 & 13,54 \\
Bolso & 14,37 & 10,64 & 01 & 60 & 2,39 & 13,12 \\
Punho & 16,10 & 10,07 & 01 & 84 & 3,77 & 20,65 \\
\hline
\end{tabular}

Fonte: os autores

Um estudo de avaliação de jalecos de 100 médicos envolvidos com procedimentos cirúrgicos demonstrou a presença de alta contaminação por Staphylococcus aureus. Os dados demonstraram uma maior positividade em regiões de punhos e bolsos, devido o possível contato direto com as feridas dos

Revista da Universidade Vale do Rio Verde, Três Corações, v. 13, n. 2, p. 152-161, 2015 
pacientes ou por contaminação das próprias mãos (FENALTE, GELATTI, 2012).

Para verificar uma possível relação entre os níveis de contaminação das três áreas estudadas, assim como entre elas e o tempo em que o jaleco se encontra em uso antes da coleta do material, determinou-se o coeficiente de correlação de Spearman (TABELA 2).

Tabela 02 - Coeficientes de correlação de Spearman (r) e os valores p entre a contaminação no peito, bolso e punho e entre estas áreas e o tempo de uso dos acadêmicos do curso de Odontologia da UNIFAL-MG. Alfenas, MG. 2012.

\begin{tabular}{ccc}
\hline Correlações & $\mathrm{r}$ & $\mathrm{p}$ \\
\hline Peito x Bolso & $0,650^{* *}$ & 0,000 \\
\hline Peito x Punho & $0,650^{* *}$ & 0,000 \\
\hline Bolso x Punho & $0,543^{* *}$ & 0,002 \\
\hline Peito x Tempo de uso & 0,192 & 0,308 \\
\hline Bolso x Tempo de uso & 0,058 & 0,760 \\
\hline Punho x Tempo de uso & 0,301 & 0,106 \\
\hline Fonte: os autores & & $* *$ Significativo a $1 \%$.
\end{tabular}

Dos resultados obtidos a partir da análise da correlação, pode-se concluir que existe uma correlação direta entre os níveis de contaminação nas três áreas pesquisadas, ou seja, percebe-se que a contaminação do jaleco é de certa forma geral, estando um indivíduo contaminado em uma região certamente estará contaminado nas outras sem diferenças significativas. Assim como encontrado por Wong (1991), Loh et al. (2000) e Nesi (2006), no presente estudo, as três áreas não se correlacionaram ao tempo de uso do jaleco o que poderia ser determinante da intensidade da contaminação, sugerindo que os jalecos se tornam rapidamente contaminados após a primeira vez de uso, como parece haver pouca diferença entre a contagem de colônias de acordo com a frequência da lavagem.

A capacitação em biossegurança é um fator primordial para a adoção das medidas de precaução-padrão, pois requerem nova aprendizagem e mudanças de hábitos por parte dos profissionais (SILVA et al., 2012).

$\mathrm{Na}$ intenção de comparar se o nível de contaminação das três áreas estudadas está associado ao tipo de tecido dos jalecos realizamos o teste de Mann-Whitney levando em conta o Rank Médio. Os resultados obtidos estão expressos na Tabela 3, o tipo de tecido com o qual os jalecos foram confeccionados não influenciou os níveis de contaminação dos mesmos, concordando com encontrado por Nesi et al.(2006). 
Tabela 03- Comparação através do teste de Mann-Whitney entre o tipo de tecido dos jalecos e o nível de contaminação na região do peito, bolso e punho dos jalecos dos acadêmicos do curso de Odontologia da UNIFAL-MG. Alfenas, MG. 2012

\begin{tabular}{ccccc}
\hline Sítios & Tipo do tecido & N & Rank Médio & p \\
\hline Peito & Microfibra & 22 & 15,64 & 0,909 \\
& Oxford & 08 & 15,13 & 0,629 \\
\hline Bolso & Microfibra & 22 & 16,00 & 0,393 \\
& Oxford & 08 & 14,13 & 16,34 \\
\hline
\end{tabular}

Fonte: os autores

Após coleta e incubação, as colônias obtidas não fermentaram o manitol que é um açúcar presente no meio de cultura, ou seja, o meio de cultura não alterou sua cor de vermelho para amarelo após o crescimento das bactérias mostrando-se manitol negativo.

Das colônias isoladas para a confirmação de que eram realmente Staphylococcus, foram realizados o método de Gram e a prova da catalase cujo os resultados mostraram cocos Gram positivos dispostos em cacho e prova da catalase positivo. Devido aos resultados dos testes de DNAse e coagulase negativos podemos concluir que as amostras coletadas foram de Staphylococcus não aureus, corroborando com os achados de Oliveira e Silva (2013). Apesar destes fazerem parte da microbiota da pele e da mucosa humana, os Staphylococcus coagulase negativos tem emergido como um dos principais agentes etiológicos causadores das Infecções Relacionadas à Assistência à
Saúde (IRAS), sendo o Staphylococcus epidermidis o mais prevalente (KLINGENBERG et al., 2007).

Neste estudo, para avaliar o perfil de sensibilidade, foram escolhidas aleatoriamente dezenove amostras para serem submetidas a 09 agentes antimicrobianos. De acordo com a Tabela 4, todas as amostras foram sensíveis a Linezulida, Sulfatrozim e Vancomicina. Foi observada sensibilidade a Amoxicilina/Clavulnato, $(94,73 \%)$, Clindamicina e Ciprofloxacina $(89,47 \%)$ concomitantemente, Oxacilina $(84,21 \%)$, Norfloxacina e Azitromicina (63,15\%) concomitantemente.

Foi encontrada resistência a Azitromicina (36,84\%), Norfloxacina $(26,31 \%)$ e Oxacilina $(15,79 \%)$ mesmo que em menor quantidade, a ocorrência de resistência neste grupo de antimicrobianos merece atenção. 
Tabela 04 - Antibiograma dos isolados de Staphylococcus não aureus obtidos dos jalecos dos acadêmicos do curso de Odontologia da UNIFAL-MG. Porcentagem de sensibilidade e resistência aos antibióticos. Alfenas, MG. 2012.

\begin{tabular}{lccc}
\hline \multicolumn{1}{c}{ Antibiótico } & \% Amostras Sensíveis & $\begin{array}{c}\text { \% Amostras } \\
\text { Intermediarias }\end{array}$ & \% Amostras Resistentes \\
\hline Amoxicilina/Clavulanato & 94,73 & 0,00 & 5,27 \\
Sulfazotrim & 100,00 & 0,00 & 0,00 \\
Oxacilina & 84,21 & 0,00 & 15,79 \\
Norfloxacina & 63,15 & 10,52 & 26,31 \\
Linezulida & 100,00 & 0,00 & 0,00 \\
Clindamicina & 89,47 & 5,26 & 5,26 \\
Ciprofloxacina & 89,47 & 10,53 & 0,00 \\
Azitromicina & 63,15 & 0,00 & 36,84 \\
Vancomicina & 100,00 & 0,00 & 0,00
\end{tabular}

Em estudos sobre a participação dos jalecos na disseminação de patógenos, verificou-se a presença de Staphylococcus aureus, Acinetobacter baumannii $e$ Klebisiella pneumoniae, que são comumente relacionados às IRAS. Estes achados reforçam a necessidade de considerar os jalecos como potencial agente de disseminação (TREAKLE et al., 2009; UNEKE, 2010).

Apesar dos alunos relatarem ter consciência do risco de que o uso do jaleco fora do ambiente clínico poderia ser uma fonte potencial de infecções cruzadas e afirmarem que o utilizam somente no ambiente de trabalho, ficou claro a contaminação do jaleco após o atendimento clínico.

Percebe-se que além da educação para conscientizar os acadêmicos sobre a importância das medidas de biossegurança é necessário orientar sobre os cuidados referentes a higiene do jaleco e seu armazenamento após cada período de trabalho, criando hábitos corretos para controle das infecções cruzadas.

\section{CONCLUSÕES}

Os resultados nos permitem concluir que os jalecos utilizados por alunos do curso de Odontologia da UNIFAL-MG apresentavamse contaminados por Staphylococcus $s p$, independente da área (sítio) do jaleco pesquisada. $\mathrm{O}$ tipo de tecido que o jaleco foi confeccionado não influenciou no nível de contaminação do mesmo.

O resultado do antibiograma mostrou uma maior sensibilidade das amostras aos antibióticos: Linezulida, Sulfazotrim e 
Vancomicina e uma menor sensibilidade aos antibióticos Azitromicina e Norfloxacina.

\section{REFERÊNCIAS}

CARDoso, A. C. M. et al. Avaliação das condições higiênico - sanitárias de jalecos e mãos de profissionais de saúde, usuários de uma unidade de alimentação e nutrição hospitalar. Rev Hig Aliment, v. 24, n. 180/181, p. 43-47, 2010.

CARVAlHO, E. L. M. et al. Aspectos de biossegurança relacionados ao uso do jaleco pelos profissionais de saúde: uma revisão da literatura. Texto Contexto Enferm, v. 18, n. 2, p. 355-360, 2009.

BAUER, A. W. et al. Antibiotic susceptibility testing by a standardized single disk method. Am. J. Clin. Pathol. v.45, n. 4, p. 493-496, 1966.

DIAS JÚNIOR, P. P. Jaleco: uso correto na hora certa, em local apropriado. 2008. Disponível em: <http://www.cdcc.usp.br/ciencia/artigos/art_4 3/editorial_ed43.html> Acesso em: 25 mar. 2010.

FENALTE, M. P.; GELATTI, L. C. Contaminação de jalecos usados pela equipe de enfermagem. Rev Fasem Ciências, v. 1, n.1, p. 39-44, 2012.

KLINGENBERG, C. et al. Persistent strains of coagulase-negative staphylococci in a neonatal intensive care unit: virulence factors and invasiveness. Clin Microbiol Infect, n. 13, p. 1100- 1111, 2007.

LOH, W.; NG, V. V.; HOLTON, J. Bacterial flora on the white coats of medical students. J Hosp Infect, v. 45, n. 1, p. 65-8, 2000.

LOVEDAY et al., Public perception and the social and microbiological significance of uniforms in the prevention and control of healthcare-associated infections: an evidence review. Br J Infec Control., v.8, n. 4, p.1021, 2007.

NESI, M. M. N. et al. Contaminação em jalecos utilizados por estudantes de odontologia. Saúde Rev, v.20, n.8, p. 47-54, 2006.

OLIVEIRA, A. C.; SILVA, M. D. M.

Caracterização epidemiológica dos microrganismos presentes em jalecos dos profissionais de saúde. Rev. Eletr.

Enferm.,n.15, v. 1, p. 80-87, 2013.

Disponível em: 
<http://dx.doi.org/10.5216/ree.v15i1.17207>. Acesso em: 19 nov. 2014.

PILONETTO, M. et al. Hospital gowns as a vehicle for bacterial dissemination in an intensive care unit. Braz. J. Infect. Dis., v. 8, n.3, p. 206-210, 2004.

SILVA, G. S. et al. Conhecimento e utilização de medidas de precaução-padrão por profissionais de saúde. Esc Anna Nery. v.16, n. 1, p. 103-110, jan-mar. 2012.

TREAKLE, A.M. et al. Bacterial contamination of health care workers' white coats. Am J Infect Control. n. 37, v. 2, p. 101- 105, 2009.

UNEKE, C.J.; IJEOMA, P.A. The potential for nosocomial infection transmission by white coat used by physicians in Nigeria: Implications for improved patient-safety initiatives. Would Health \&Population. n. 11, v. 3, p. 44- 54, 2010.

WONG D.; NYE K.; HOLLIS P. Microbial flora on doctors, white coats. BMJ, v. 103, p. 21-25, 1991. 